\title{
Response to'Plasma proteins present in osteoarthritic synovial fluid can stimulate cytokine production via Toll-like receptor $4^{\prime}$
}

\author{
Francesca Oliviero*1, Anna Scanu', Jean-Michel Dayer², Ugo Fiocco', Paolo Sfriso' and Leonardo Punzi' \\ See related research by Sohn et al., http://arthritis-research.com/content/14/1/R7, and related letter by Sohn et al., \\ http://arthritis-research.com/content/14/5/406
}

We read with great interest the article by Sohn and colleagues published in the February 2012 issue of Arthritis Research \& Therapy [1]. Using proteomic analysis, the authors were able to show that plasma proteins present in osteoarthritic synovial fluid are able to induce inflammatory cytokine production via interaction with Toll-like receptor 4 , thus contributing to the low-grade inflammation associated with osteoarthritis.

We would like to add some observations concerning our data on the immunomodulatory effect of plasma on inflammation induced by calcium pyrophosphate crystals, which are considered danger signals to the innate immune system and, in osteoarthritis, provoke inflammation inducing the production and the release of proinflammatory mediators [2].

When calcium crystals are used in vitro, cells need to be preactivated with phorbol myristate acetate or, less frequently, with lipopolysaccharide because pure crystals alone are unable to induce IL-1 $\beta$. In vivo, various plasma proteins coating onto the crystal surface have been shown to enhance phagocytic recognition of crystals by cells [3], leading to activation of some inflammatory pathways such as NALP-3 inflammasomes [2].

In our experimental settings, using low doses of phorbol myristate acetate to prime a human monocytic cell line (THP-1) to crystals, we observed that healthy human plasma is able to enhance the inflammatory response to crystals in a dose-dependent manner. Interestingly, the effect on the release of IL-1 $\beta$ and IL- 8 was stronger when plasma was replaced by serum collected from the same blood sample (Figure 1).

\footnotetext{
*Correspondence: francesca.oliviero@unipd.it

'Department of Medicine, Rheumatology Unit, University of Padova, Via Giustiniani 2, 35128 Padova, Italy

Full list of author information is available at the end of the article
}

Hypothesizing the presence of some inhibitory components in plasma, we decided to stimulate cells by adding to the medium physiological plasmatic concentrations of fibrinogen, the clotting factor not contained in serum. While fibrinogen alone had no evident effect on IL-1 $\beta$ production, it was able to enhance the inflammatory action of calcium pyrophosphate crystals in a dose-dependent manner. The effect was quite different with regard to the release of IL-8, however, which was enhanced even in the absence of calcium pyrophosphate crystals (Figure 2).

Fibrinogen has been shown to possess both inflammatory and anti-inflammatory properties depending on its concentration, and the effect is mediated by Toll-like receptor 4 [4]. In our case, fibrinogen showed a direct effect both on cells and on crystals, with an overall effect on the modulation of inflammation.

Our results prompt us to speculate that fibrinogen is able to stimulate/modulate the inflammatory response to calcium crystals.

\section{Abbreviations}

$\mathrm{IL}$, interleukin.

\section{Competing interests}

The authors declare that they have no competing interests.

\section{Acknowledgements}

The authors are grateful to Mrs Linda Inverso Moretti for editing the English version of this manuscript

\section{Author details}

'Department of Medicine, Rheumatology Unit, University of Padova, Via Giustiniani 2, 35128 Padova, Italy. ${ }^{2}$ Faculty of Medicine, CMU, 1, rue MichelServet, $\mathrm{CH}-1211$ Geneva, Switzerland.

\section{Published: 12 September 2012}

\footnotetext{
References

1. Sohn DH, Sokolove J, Sharpe O, Erhart JC, Chandra PE, Lahey LJ, Lindstrom TM, Hwang I, Boyer KA, Andriacchi TP, Robinson WH: Plasma proteins present in osteoarthritic synovial fluid can stimulate cytokine production via Toll-like receptor 4. Arthritis Res Ther 2012, 14:R7.

2. Busso N, So A: Microcrystals as DAMPs and their role in joint inflammation.
} 


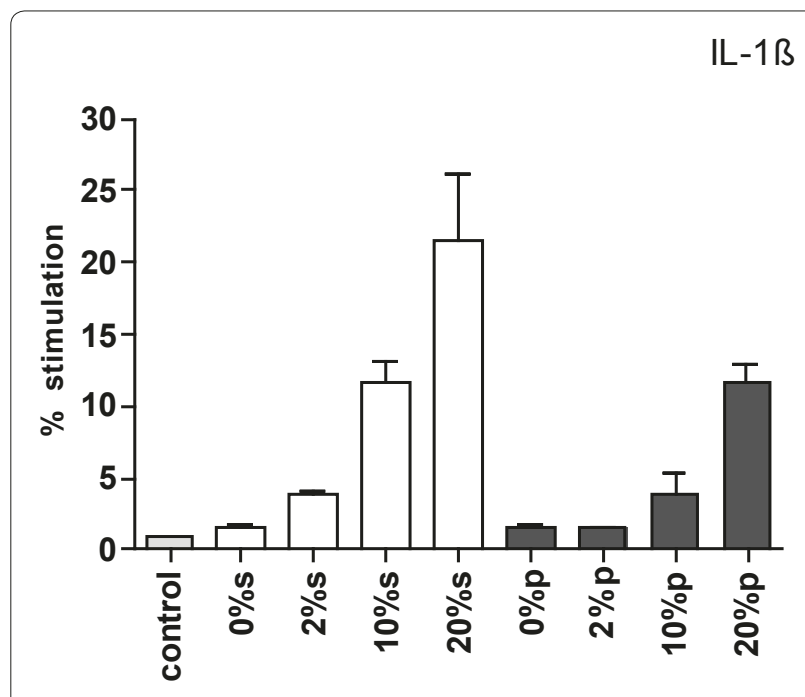

IL-8

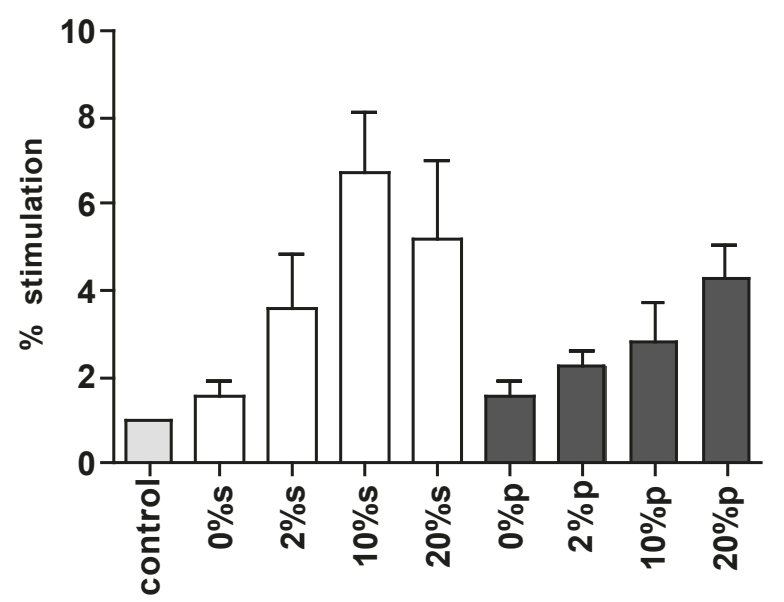

Figure 1. Effect of serum and plasma on IL-1 $\beta$ and IL-8 production induced by calcium pyrophosphate crystals. The effect of serum (s) and plasma ( $p$ ) at various percentages on the production of IL-1 $\beta$ and IL-8 induced by calcium pyrophosphate crystals $(0.025 \mathrm{mg} / \mathrm{ml})$. Results are expressed as the percentage of stimulation with respect to the control. Bars are the mean and standard deviation of three separate experiments.

Rheumatology (Oxford) 2012, 51:1154-1160.

3. Burt HM, Jackson JK: Enhancement of crystal induced neutrophil responses by opsonisation of calcium pyrophosphate dihydrate crystals. Annals Rheum Dis 1993, 52:599-607.

4. Smiley ST, King JA, Hancock WW: Fibrinogen stimulates macrophage chemokine secretion through toll-like receptor 4. J Immunol 2001, 167:2887-2894.

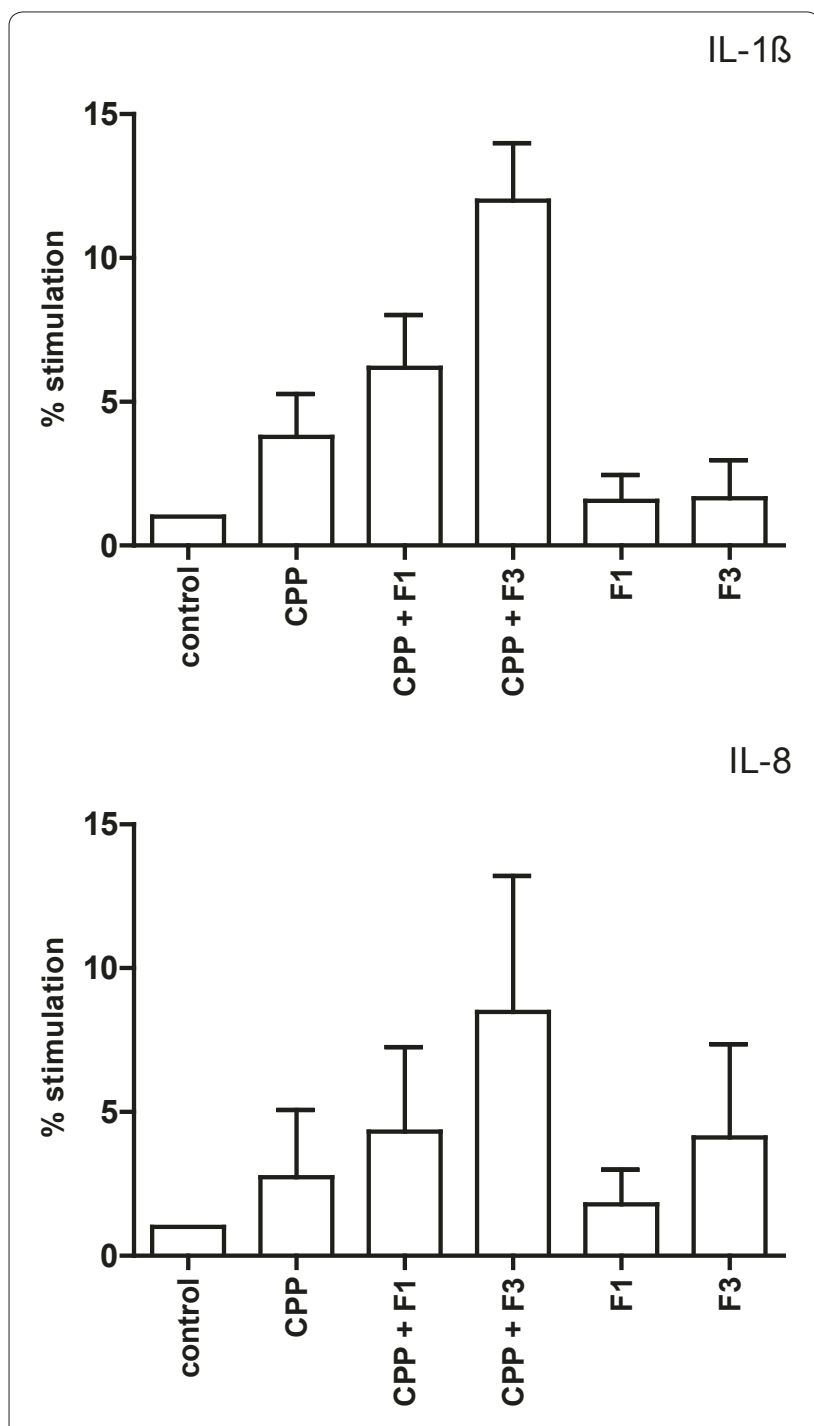

Figure 2. Effect of fibrinogen on IL-1 $\beta$ and IL-8 production induced by calcium pyrophosphate crystals. The effect of fibrinogen ( $1 \mathrm{mg} / \mathrm{ml}, \mathrm{F} 1 ; 3 \mathrm{mg} / \mathrm{ml}, \mathrm{F} 3$ ) on the production of IL-1 $\beta$ and IL-8 induced by calcium pyrophosphate crystals (CPP; $0.025 \mathrm{mg} / \mathrm{ml}$ ). Results are expressed as the percentage of stimulation with respect to the controls. Bars are the mean and standard deviation of three separate experiments. doi:10.1186/ar3863

Cite this article as: Oliviero F, et al:. Response to 'Plasma proteins present in osteoarthritic synovial fluid can stimulate cytokine production via Toll-like receptor 4'. Arthritis Research \& Therapy 2012, 14:405. 